\title{
Safety and efficacy of stereotactic body radiotherapy as primary treatment for vertebral metastases: a multi-institutional analysis
}

Matthias Guckenberger ${ }^{1,12^{*}}$, Frederick Mantel ${ }^{1}$, Peter C Gerszten ${ }^{2,3}$, John C Flickinger ${ }^{2,3}$, Arjun Sahgal ${ }^{4}$, Daniel Létourneau ${ }^{5}$, Inga S Grills ${ }^{6}$, Maha Jawad ${ }^{6}$, Daniel K Fahim, John H Shin ${ }^{8}$, Brian Winey', Jason Sheehan ${ }^{10}$ and Ron Kersh ${ }^{11}$

\begin{abstract}
Purpose: To evaluate patient selection criteria, methodology, safety and clinical outcomes of stereotactic body radiotherapy (SBRT) for treatment of vertebral metastases.

Materials and methods: Eight centers from the United States $(n=5)$, Canada $(n=2)$ and Germany $(n=1)$ participated in the retrospective study and analyzed 301 patients with 387 vertebral metastases. No patient had been exposed to prior radiation at the treatment site. All patients were treated with linac-based SBRT using cone-beam CT image-guidance and online correction of set-up errors in six degrees of freedom.

Results: 387 spinal metastases were treated and the median follow-up was 11.8 months. The median number of consecutive vertebrae treated in a single volume was one (range, 1-6), and the median total dose was 24 Gy (range 8-60 Gy) in 3 fractions (range 1-20). The median EQD2 10 was $38 \mathrm{~Gy}$ (range 12-81 Gy). Median overall survival (OS) was 19.5 months and local tumor control (LC) at two years was $83.9 \%$. On multivariate analysis for OS, male sex $(p<0.001 ; H R=0.44)$, performance status $<90(p<0.001 ; H R=0.46)$, presence of visceral metastases $(p=0.007$; $H R=0.50)$, uncontrolled systemic disease $(p=0.007 ; H R=0.45)$, $>1$ vertebra treated with SBRT $(p=0.04 ; H R=0.62)$ were correlated with worse outcomes. For LC, an interval between primary diagnosis of cancer and SBRT of $\leq 30$ months $(p=0.01 ; H R=0.27)$ and histology of primary disease ( NSCLC, renal cell cancer, melanoma, other) $(p=0.01 ; H R=0.21)$ were correlated with worse LC. Vertebral compression fractures progressed and developed de novo in $4.1 \%$ and $3.6 \%$, respectively. Other adverse events were rare and no radiation induced myelopathy reported.
\end{abstract}

Conclusions: This multi-institutional cohort study reports high rates of efficacy with spine SBRT. At this time the optimal fractionation within high dose practice is unknown.

\section{Introduction}

A single fraction of conventional radiotherapy with 8 Gy has been recommended for painful vertebral metastases [1-3]. However, this conventional radiotherapy is associated with only short term pain relief of $3-6$ months. This might be sufficient for metastatic patients with short life expectancy. However, today validated scores

\footnotetext{
* Correspondence: Matthias.Guckenberger@usz.ch

'Department of Radiation Oncology, University of Wuerzburg, Wuerzburg,

Germany

${ }^{12}$ Department of Radiation Oncology, University of Zurich, Zurich, Switzerland

Full list of author information is available at the end of the article
}

are available to select a subgroup of patients with longer overall survival [4]. In parallel, improvements of overall survival due to more effective systemic treatments in many cancer types motivated the evaluation of radiation technology to maximize pain control and local control for the long term. With image guidance (IGRT), intensity modulated radiotherapy (IMRT), precision patient positioning devices and a fundamental shift in our understanding of the radiobiology of high dose radiation, Stereotactic Body Radiotherapy (SBRT) has emerged for the treatment of spinal metastases.

SBRT achieves local tumor control rates exceeding $90 \%$ in early stage non-small cell lung cancer (NSCLC).

\section{Ciomed Central}

(c) 2014 Guckenberger et al.; licensee BioMed Central Ltd. This is an Open Access article distributed under the terms of the Creative Commons Attribution License (http://creativecommons.org/licenses/by/4.0), which permits unrestricted use, distribution, and reproduction in any medium, provided the original work is properly credited. The Creative Commons Public Domain Dedication waiver (http://creativecommons.org/publicdomain/zero/1.0/) applies to the data made available in this article, unless otherwise stated. 
The methodology of image-guided SBRT was transferred from lung cancer to vertebral metastases aiming at more rapid and especially long-term pain and tumor control by more intense irradiation [5]. Spine SBRT was quickly adopted in the radiotherapy community [6]. However, this broad clinical implementation is supported by only few prospective trials $[7,8]$ : evidence is mostly based on small, retrospective, and single-institution analyses.

Although the risk of radiation induced myelopathy is low after spine SBRT $[9,10]$, unexpectedly high rates of "new" toxicities like vertebral compression fracture have been described [11]. These observations combined with a lack of standardization of spine SBRT practice indicate that larger studies with longer follow-up as well as prospective trials are required to establish the methodology and value of SBRT in the multidisciplinary management of spinal metastases. Therefore, it was the aim of this study to establish a multi-institutional database of spine SBRT and to analyze patient selection criteria, methodology, safety and clinical outcome after spine SBRT.

\section{Materials and methods}

Eight international centers from the United States $(n=5)$, Canada $(\mathrm{n}=2)$ and Germany $(\mathrm{n}=1)$ participated in this retrospective study. The local ethics committee approved participation in this study in all eight centers. The study is based on 301 patients treated for 387 vertebral metastases (11 to 118 per institution) between 2004 and 2013; 370 of 387 SBRT treatments were performed 2008 and later.

A homogeneous patient cohort was analyzed in this study: SBRT was used as re-irradiation in none of the cases and no patient suffered from symptomatic spinal cord compression. All centers are members of the "Elekta Spine SBRT Research Consortium" and therefore, identical treatment delivery technology was used in all treatments. Patients were treated with linac based SBRT using daily cone-beam CT based image-guidance, online correction of set-up errors in six degrees of freedom using the robotic HexaPod ${ }^{\mathrm{m}}$ couch (Elekta $A B$, Stockholm, Sweden) and intensity modulated radiotherapy (IMRT) was delivered using a multileaf collimator with $4 \mathrm{~mm}$ leaf width (BeamModulator ${ }^{\mathrm{mw}}$, Elekta $\mathrm{AB}$, Stockholm, Sweden).

Other details of treatment planning and delivery were not standardized between institutions and will therefore be presented in the results part of the manuscript.

In order to correlate irradiation doses with clinical results, biological equivalent doses in 2 Gy fractions (EQD2) were calculated: an $\alpha / \beta$-ratio of 10 Gy was assumed for spinal metastases and an $\alpha / \beta$-ratio of 2 Gy for the spinal cord. The EQD2 was calculated using the linear quadratic model $(\mathrm{n}=$ number of fractions; $\mathrm{d}=$ single fraction dose):

$$
E Q D 2(G y)=n^{*} d^{*}(d+\alpha / \beta) /(2+\alpha / \beta)
$$

Imaging (CT, MRI or FDG-PET CT) was required for assessment of local tumor control (LC) and local failure was defined as tumor regrowth in the treated volume according to institutional protocol. Progressive clinical symptoms or pain without local tumor recurrence in imaging were not sufficient for definition of local failure.

Pain at the treated vertebral level was categorized into pain-free, mild-to-moderate pain and severe pain prior to SBRT and at the last follow-up. If detailed information as the visual analog scale was available, pain-free, mildto-moderate pain and severe pain were equivalent to scores of 0, 1-5 and 6-10, respectively.

Statistical analyses were performed with Statistica X (Statsoft, Tulsa OK), and all statistical tests were twosided. OS was evaluated per patient and all other endpoints per SBRT treatment. The Pearson chi-square/ Fisher's Exact test and Kruskal-Wallis ANOVA were used to compare categorical and continuous variables between groups, respectively. Receiver Operating Characteristics (ROC) curves were used to test prognostic factors (irradiation dose) in predicting outcome, with their performances measured based on the area under the ROC curve. Estimated likelihood of events was calculated using the Kaplan Meier method with start of follow-up on the last day of SBRT treatment. The logrank test was used to compare differences between curves in univariate analysis. Multivariate analysis was performed using Cox-proportial Hazard method with backward exclusion of non-significant variables; all variables, which were statistically significant in the univariate analysis, were included into the multivariate analysis. A p-value of $\leq 0.05$ was considered statistically significant.

\section{Results}

\section{Patient and treatment characteristics}

Patient characteristics and characteristics of the treated vertebral metastases are listed in Table 1 . Inter-institutional variability in patient selection criteria is illustrated in Figure 1 . The majority of patients presented with a good performance status prior to SBRT (median Karnofsky performance status 90). About one quarter of the patients were treated for a solitary vertebral metastasis without further evidence of malignancy; additional bone and visceral metastases were present in $62.9 \%$ and $42.3 \%$ of the patients, respectively. Patients were free from epidural disease extension in 41.8\% (Bilsky score 0). Lesions had an osteolytic component in $72.3 \%$ resulting in a 
Table 1 Patient $(n=301)$ and lesion $(n=387)$ characteristics; percentages are given per SBRT treatment

\begin{tabular}{|c|c|c|c|}
\hline Characteristic & Median & Range & Proportion (\%) \\
\hline Age (years) & 61.3 & $9-91$ & \\
\hline Performance status & 90 & $40-100$ & \\
\hline Sex (male) & & & 55.1 \\
\hline Interval PD to SBRT (years) & 2.5 & $0-41$ & \\
\hline \multicolumn{4}{|l|}{ Primary disease } \\
\hline Breast & & & 20 \\
\hline $\mathrm{RCC}$ & & & 19 \\
\hline NSCLC & & & 16 \\
\hline Other & & & 45 \\
\hline \multicolumn{4}{|l|}{ Pain prior to SBRT } \\
\hline No & & & 18.2 \\
\hline Yes & & & 81.8 \\
\hline Solitary metastasis (yes) & & & 23.0 \\
\hline $\begin{array}{l}\text { Systemic disease considered as } \\
\text { controlled prior to SBRT (yes) }\end{array}$ & & & 32.0 \\
\hline $\begin{array}{l}\text { Cancer treated with curative intend } \\
\text { at primary diagnosis (yes) }\end{array}$ & & & 67.7 \\
\hline Additional bone metastasis (present) & & & 62.9 \\
\hline Visceral metastases (present) & & & 42.3 \\
\hline Bilsky Score 0 (yes) & & & 41.8 \\
\hline $\begin{array}{l}\text { Paraspinal involvement of spine } \\
\text { metastasis (yes) }\end{array}$ & & & 44.8 \\
\hline $\begin{array}{l}\text { Osteolytic component of spine } \\
\text { metastasis (yes) }\end{array}$ & & & 72.3 \\
\hline $\begin{array}{l}\text { Compression fracture of spine } \\
\text { metastasis (yes) }\end{array}$ & & & 19.8 \\
\hline
\end{tabular}

preexisting compression fracture rate of the treated vertebra in $19.8 \%$.

Treatment characteristics are summarized in Table 2. A dedicated MRI and FDG-PET were used for target and organ-at-risk definition in $85 \%$ and $18 \%$, respectively. Patients were immobilized using the BodyFix ${ }^{\mathrm{TM}}$ (Elekta $A B$, Stockholm, Sweden) system (80.6\%), a thermoplastic mask (11.9\%), a combination of both (3.5\%) or other devices (4\%). Step-and-shoot IMRT was practiced in $96 \%$ of all cases, and an anatomical target volume concept was used in the majority of the cases (61\%) [12]. A median of one vertebrae (1-6) in one single target volume was treated with median 3 irradiation fractions (1-20) to a median prescription dose of 24 Gy $(10-60$ Gy). The spinal cord, thecal sac and spinal canal formed the basis for generation of the planning risk volume (PRV-SC) in $33.4 \%, 22.3 \%$ and $42.3 \%$, respectively, and a PRV margin of 1-2 mm was used in $85 \%$ of the cases. The maximum point dose to the PRV-SC was median 10 Gy (maximum 65 Gy). After calculation of 2 Gy equivalent doses, $90 \%$ of all SBRT treatments were performed with prescription PTV doses and maximum PRV-SC doses of 27-65 Gy (EQD2 10 ) and 5-59 Gy (EQD22), respectively. Variability of doses to the PTV and PRV-SC and the association between PTV and PRV-SC doses are illustrated in Figure 2.

\section{Clinical outcome in the total patient population}

The median follow-up was 11.8 months (0-105 months), median OS was 19.5 months; one-year and two-years OS were $64.9 \%$ and $43.7 \%$ (Figure 3), respectively. Univariate analysis was performed for patient and treatment factors associated with OS and significant parameters were included into multivariate analysis. The following characteristics were significantly associated with worse OS: male sex $(\mathrm{p}<0.001 ; \mathrm{HR}=0.44)$, performance status $<90(\mathrm{p}<0.001 ; \mathrm{HR}=0.46)$, presence of visceral metastases $(\mathrm{p}=0.007$; $\mathrm{HR}=0.50)$, uncontrolled systemic disease $(\mathrm{p}=0.007 ; \mathrm{HR}=0.45)$, $>1$ vertebra treated with SBRT $(\mathrm{p}=0.04 ; \mathrm{HR}=0.62)$.

LC was assessed using CT (25.4\%), MRI (63.2\%), FDG PET (1.2\%) or FDG PET-CT (10.2\%); follow-up was too short for analysis of local tumor control in $15 \%$. Oneyear and two-years LC were $89.9 \%$ and $83.9 \%$ (Figure 4), respectively. Median time to development of local failure was 9 months ( $1-55$ months).

Univariate analysis was performed for patient and treatment factors associated with local tumor control and significant parameters were included into multivariate analysis. The following characteristics were significantly associated with worse outcome: interval between primary diagnosis of cancer and SBRT of $\leq 30$ months ( $\mathrm{p}=0.01 ; \mathrm{HR}=0.27)$ and histology of primary disease (NSCLC, renal cell cancer, melanoma, other) $(\mathrm{p}=0.01$; $\mathrm{HR}=0.21$ ).

Prior to SBRT, patients were pain-free, suffered from mild/moderate pain and severe pain in $18.2 \%, 64.9 \%$ and $16.9 \%$, respectively. Detailed pain response at the treated spinal level after a median follow-up of 11.5 months is illustrated in Figure 5. Patients being pain-free, suffering from mild/moderate and severe pain prior to SBRT were pain-free at the time of the last clinical assessment in $76.8 \%, 56.3 \%$ and $43.8 \%$, respectively. After uni- and multivariate analyses, no patient or treatment characteristic was significantly associated with improved pain control.

Acute toxicity was mild in the majority of the patients: grade 3 toxicity was observed in only 2 patients (Table 3 ). Median follow-up for assessment of long-term toxicity was 11.5 months, maximum 105 months. Progressive of new vertebral compression fractures were diagnosed in 30 cases $(7.8 \%)$, of which the fracture was newly developed after SBRT in 14 cases (3.6\%) and progressive after SBRT in 16 cases (4.1\%). No case of radiation-induced myelopathy (RIM) was observed. 


\section{Comparison of patients treated with 1-5 and 6-20 SBRT fractions}

Patient characteristics and clinical outcome were compared between SBRT with 1-5 fractions $(\mathrm{n}=352)$ and hypo-fractionated SBRT with 6-20 fractions $(n=35)$. Hypo-fractionated SBRT was practiced in patients, who had received palliative chemotherapy prior to SBRT less

Table 2 SBRT treatment $(n=387)$ characteristics

\begin{tabular}{llll}
\hline Characteristic & Median & Range & Proportion (\%) \\
\hline $\begin{array}{l}\text { Number of vertebras treated in } \\
\text { one target volume }\end{array}$ & $1-6$ & \\
$\begin{array}{l}\text { Number of vertebras treated in } \\
\text { one target volume } n=1\end{array}$ & & 70.4 \\
$\begin{array}{l}\text { Number of vertebras treated in } \\
\text { one target volume } n=2-3\end{array}$ & & 24.7 \\
$\begin{array}{l}\text { Number of vertebras treated in } \\
\text { one target volume } n=4-6\end{array}$ & & & 4.9 \\
$\begin{array}{l}\text { Treatment fractions } \\
\text { Treatment fractions } n=1\end{array}$ & 3 & $1-20$ & \\
$\begin{array}{l}\text { Treatment fractions } n=2-5 \\
\text { Treatment fractions } n=6-20\end{array}$ & & & 39.5 \\
Prescription dose (Gy) & 24 & $8-60$ & 5.4 \\
PTV (cm ${ }^{3}$ ) & 34 & $0.8-721$ & \\
Max. point dose PRV spinal cord & 10 & $2-65$ & \\
Prescription dose (EQD2/10 Gy) & 37.7 & $12-81$ & \\
Max. point dose PRV spinal cord & 22.4 & $2-112$ & \\
(EQD2/2 Gy) & & & \\
\hline
\end{tabular}

frequently (17\% vs 61\%; $\mathrm{p}<0.001)$ and who suffered from pain less frequently (69\% vs $84 \%$; $\mathrm{p}=0.03)$; all other patient characteristics were not statistically different. Metastatic lesions treated with hypo-fractionated SBRT were osteolytic more frequently ( $94 \%$ vs $70 \% ; \mathrm{p}=0.001$ ), were characterized by a compression fracture prior to SBRT more frequently ( $37 \%$ vs $18 \% ; \mathrm{p}=0.01)$ and had a distribution with higher Bilsky scores $(\mathrm{p}<0.001)$. Irradiation doses were significantly higher in patients treated with hypo-fractionated SBRT: EQD2 ${ }_{10}$ PTV prescription doses

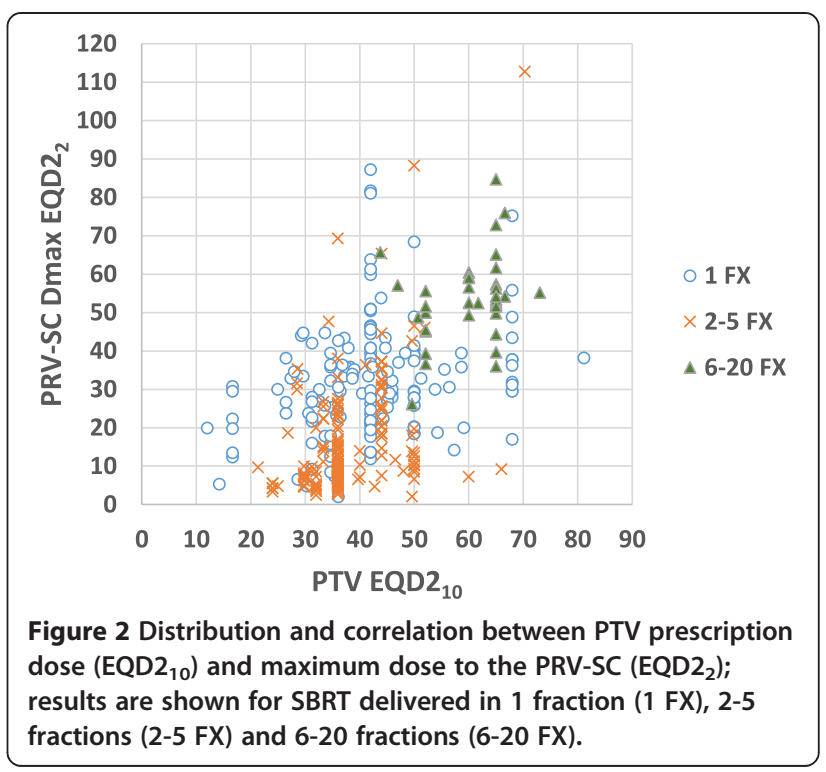




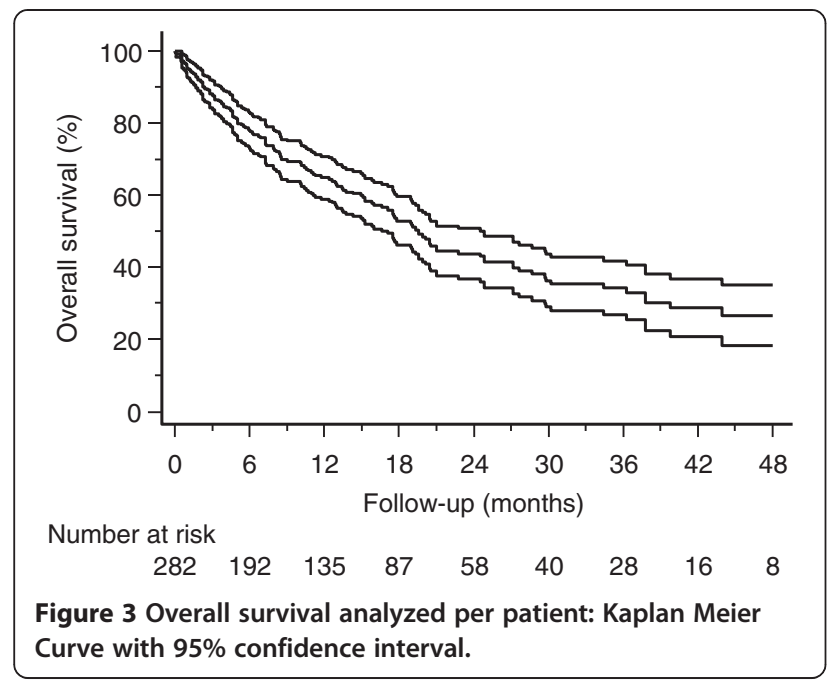

were 60 Gy and 40 Gy on average $(\mathrm{p}<0.001)$, respectively and EQD2 2 maximal PRV spinal cord doses were $54 \mathrm{~Gy}$ and 23 Gy $(\mathrm{p}<0.001)$, respectively. In terms of clinical outcome, median OS was 19 months and 20 months after SBRT with $<5$ and 6-20 SBRT fractions $(\mathrm{p}=0.89)$, respectively. Local tumor was not different as well: two year LC was $84 \%$ and $82 \%(p=0.4)$, respectively. The development of new fractures after SBRT was not correlated with the number of SBRT fractions.

\section{Discussion}

This is the largest study reporting detailed data regarding patient selection criteria, clinical practice and outcome of spine SBRT in a multi-institutional environment. Substantial variability was observed in major aspects of spine SBRT, despite the fact that nearly identical linac-based SBRT technologies were utilized at all eight participating institutions. This inter-institutional variability is most

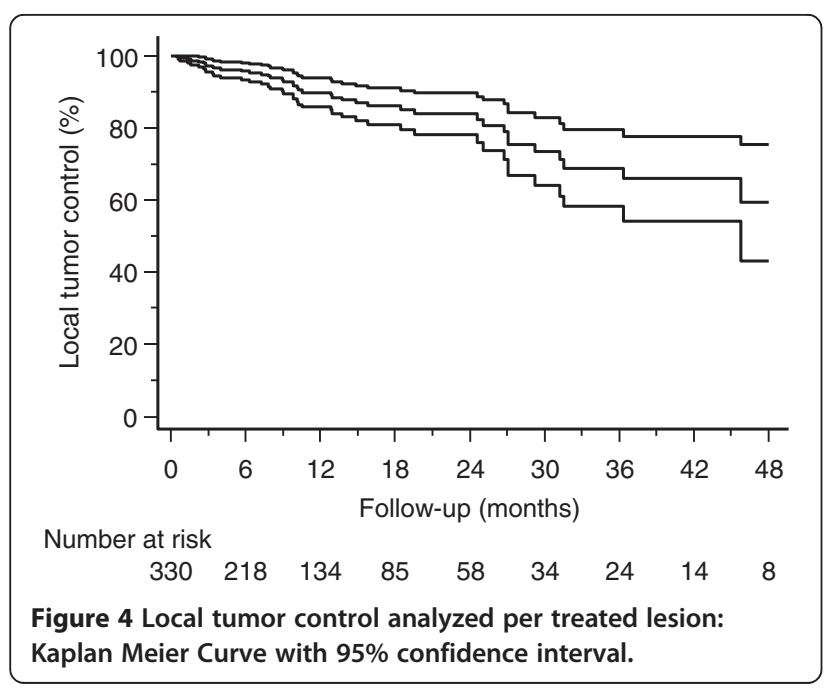

likely explained by similar variability of SBRT practice in the literature and the lack of clearly established patient selection criteria and practice guidelines [13]. Results of our study may therefore be considered as representative for current spine SBRT practice in the radiotherapy community.

Whereas some centers explicitly selected patients with long life expectancy for their spine SBRT practice, this was not done by other institutions. The proportion of patients free from visceral metastases prior to SBRT ranged between $31.6 \%$ and $73.8 \%$ and oligomatastatic disease was stated as the primary reason for SBRT in between $23.7 \%$ and $100 \%$ of institutional cases. Similar variability was observed for relevant treatment characteristics. Fractionation ranged from single-fraction radiosurgery to hypo-fractionated SBRT; one institution treated the majority of their cases with 20 fractions, which is not considered as SBRT based on the US SBRT definition. However, treatment was planned and delivered with identical accuracy as single fraction radiosurgery and the fractionation of $20 \times 3$ Gy equates to a radiosurgical dose of $>23$ Gy rendering this approach highly biologically active [14].

Despite this variability in patient and treatment characteristics, toxicity was minimal in this study. Most importantly, no single case of RIM was observed. The average time to development of RIM after conventional radiotherapy is approximately 18 months [15]. Gibbs et al. reported the largest study of six RIM cases in 1075 spine SBRT cases [9]: their 6 months time interval to development of RIM appears shorter compared to conventional radiotherapy. Follow-up was longer than 6 months and 18 months in 192 and 87 of our patients, respectively, indicating a sufficiently long follow-up for reliable analysis of RIM. The absence of RIM in our study is especially encouraging as epidural disease with a Bilsky score of $>0$ was present in $58 \%$ of our patients [16]. The absence of RIM maybe explained by several safety measures, which were consistently practiced in our patient cohort: 1) use of the PRV concept for the spinal cord, 2) maximum EQD2 2 doses to the PRV spinal cord $\leq 60$ Gy in $>95 \%$ of the cases, 3) daily volumetric image-guidance with online correction of set-up errors in six degrees of freedom and 4) use of customized patient immobilization for minimization of intra-fractional patient motion. These measures might therefore be recommended for safe practice of spine SBRT.

Vertebral compression fractures were observed in only $7.8 \%$ of the treatments and half of them were progressive fractures, which existed prior to SBRT. Compression fractures are more frequently described in the literature with rates of $11-39 \%[11,17,18]$. Based upon these limited data available, very high single fraction doses $>20$ Gy appear to be associated with compression fractions, and 


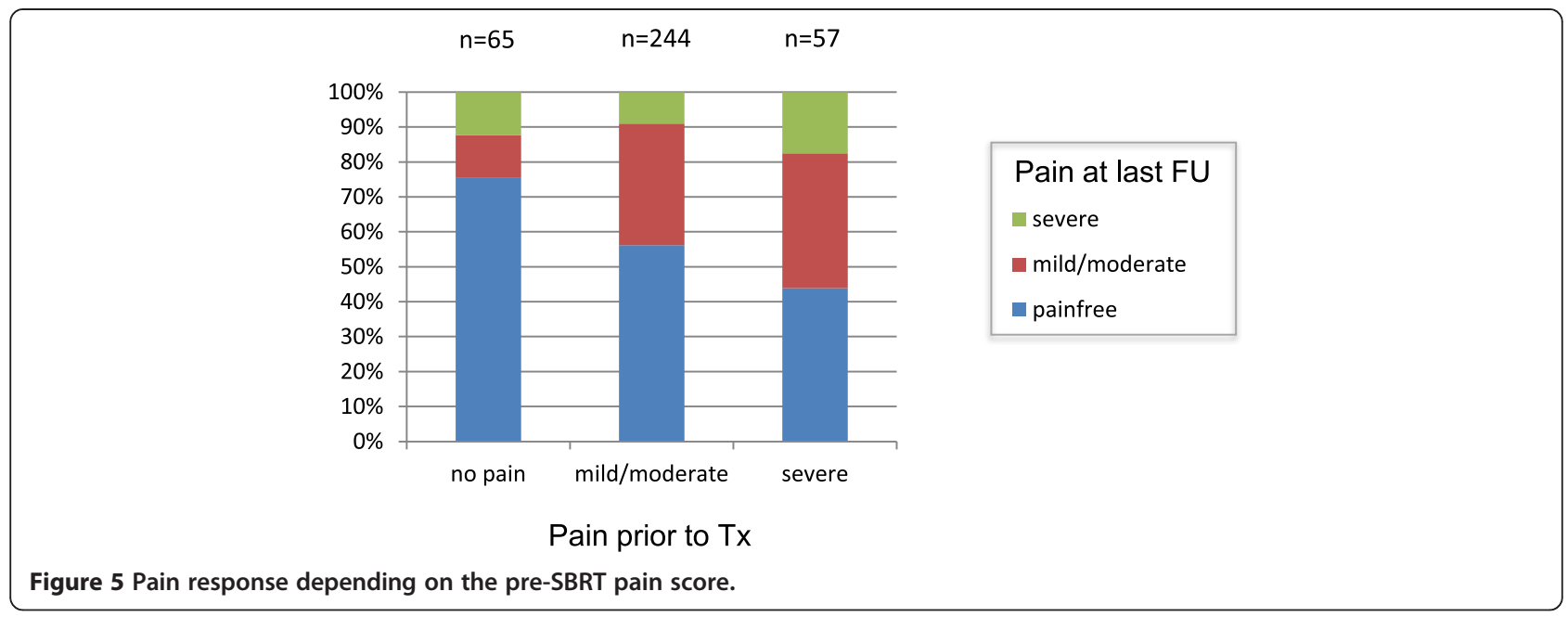

this might explain the low rate of toxicity in the current study: only 22/387 cases were treated with such high single fraction doses.

There is some controversy whether or not the increased cost and workload associated with SBRT is appropriate in the palliative setting of vertebral metastases [19]. Indeed, OS is short in unselected patients treated with conventional radiotherapy for painful vertebral metastases: Mizimoto et al. reported a median OS of only 5.9 months in 544 patients [20] and van der Linden reported a median OS of 7 months in a cohort of 342 patients, who were randomized between a single fraction of 8 Gy and $6 \times 4$ Gy [21].

However, a substantially longer OS of median 19.5 months was observed in the current study. Based on the fact that conventional radiotherapy achieves pain control only for the short duration of half a year [22-25], the majority of the patients in this study were at risk for recurring pain if conventional radiotherapy would have been performed. It is also important to put this favorable overall survival rate into the perspective of locally advanced NSCLC for example, where median OS is of similar magnitude despite aggressive multimodal treatment with curative intent [26,27].

Table 3 Absolute number of patients where acute toxicity was assessed and proportion of patients with grade 0-3 toxicity

\begin{tabular}{llll}
\hline & Dermatitis & Dysphagia & Pain \\
\hline Toxicity assessment available $(\mathrm{n})$ & 281 & 283 & 304 \\
Grade $0(\%)$ & 96.1 & 89.8 & 83.9 \\
Grade 1 (\%) & 3.9 & 9.5 & 9.6 \\
Grade 2 (\%) & 0 & 0.7 & 5.9 \\
Grade 3 (\%) & 0 & 0 & 0.7 \\
\hline
\end{tabular}

OS varies substantially between studies using SBRT for treatment of vertebral metastases. Favorable OS was reported by Wang et al. with a median OS of 23 months in 149 patients, where SBRT was used as primary treatment and re-irradiation in a prospective phase II study [7]. Median OS was as long as 30 months in 61 patients treated with single fraction radiosurgery in a phase I/II study [28]. Whether the favorable OS in this study and the studies above is a result of the applied patient selection criteria or whether SBRT in an oligometastatic disease setting contributes to prolonged OS remains to be evaluated. In contrast, Amdur et al. reported a 1-year OS of only $25 \%$ in 25 patients treated within a phase II study of single fraction radiosurgery [29]; Schipani et al. reported a median OS of 8 months [30], Heron et al. reported a median OS of 13 months [31]. A recursive partitioning analysis to predict OS was performed by Chao et al., and the three factors of age, Karnofsky performance status and the time from primary diagnosis to SBRT allowed differentiation of median OS between 2.4 months and 21.1 months [32]. In our study, mulitvariate analysis identified several clinical parameters, which were correlated with OS: gender, performance status, presence of visceral metastases, uncontrolled systemic disease, number of involved vertebras. These factors might help in the selection of patients with long life expectancy for SBRT, but validation is required.

In this context of favorable OS, long-term local tumor control was observed with actuarial rates of $89.9 \%$ and $83.9 \%$ at one and two years, respectively. This is in agreement with other reports of spine SBRT, where long-term local tumor control was achieved in $>80 \%$ of the cases $[28,31,33-37]$. Histology was significantly correlated with local tumor control and worse outcome was observed in histologies known to be less radiosensive: NSCLC, renal cell cancer and melanoma. A similar 
correlation was described by Heron et al. [31] but not by other studies [28,33].

A dose-response relationship was expected for achievement of LC, but such correlation was not observed. Prescribed physical doses and biological effective doses were not correlated with LC. Additionally, maximum doses to the PRV spinal cord and pre-SBRT Bilsky score were not significant as well, factors which should be correlated with minimum PTV doses [33,38]. Several but not all studies $[28,34]$ reported that higher SBRT do result in better LC, but there is no consensus about the detailed dose and fractionation. Laufer et al. reported improved outcome after high-dose (median total dose 27 Gy in 3 fractions) compared to low dose SBRT (median total dose 30 Gy in 5 or 6 fractions) [33]. Al-Omair et al. described better LC after 18-26 Gy in 1-2 fractions compared to 18-40 Gy in 3-5 fractions [38]. In contrast, LC was better after multiple-fraction compared to single fraction SBRT in the study by Heron et al. [31]. Lovelock et al. not only evaluated prescribed doses but performed a more detailed dosimetrical analysis and minimum PTV doses $>15$ Gy were significantly associated with better LC [35]. Based on potential variability in the method of dose prescription in this multicenter study, a detailed dosimetrical analysis similar to Lovelock et al. is currently underway. Additionally, radiological assessment of local tumor control or tumor recurrence is difficult in many cases and has been analyzed systematically only very recently [39]; this lack of established criteria for local tumor control might influence our multicenter analysis as well.

Finally, long-term LC was found to be associated with long-term pain control. The high rates of complete pain response ranging between $77 \%$ and $44 \%$ (depending on the pre-SBRT pain score) appear promising compared to complete pain response rates of only $25-40 \%$ after conventional palliative radiotherapy [22-25]. Unfortunately, the retrospective nature of this study did not allow for a longitudinal pain assessment as well as analysis of pain medication.

Strengths of this study include the large number of 387 SBRT treatments performed at eight experienced international centers. A homogeneous patient cohort of primary SBRT excluding re-irradiated patients and excluding patients treated for symptomatic spinal cord compression was analyzed. All patients were treated with linac-based SBRT using identical equipment. Follow-up was sufficiently long with a median of 11.7 months. Weaknesses of this study are the retrospective nature of our multi-institutional analysis.

\section{Conclusions}

Linac based SBRT for vertebral metastases was determined to be safe in this multi-institutional environment with no case of radiation-induced myelopathy. Use of the PRV concept for the spinal cord, maximum EQD2 2 doses to the PRV spinal cord $\leq 60$ Gy, daily volumetric image-guidance with online correction of set-up errors in six degrees of freedom and the use of customized patient immobilization are recommended measures for safe SBRT practice. In a patient cohort with favorable OS, SBRT achieved high rates of long-term local tumor control, which appears better compared to conventional radiotherapy alone.

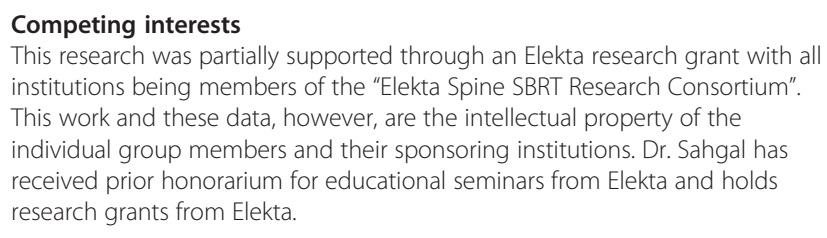
institutions being members of the "Elekta Spine SBRT Research Consortium". This work and these data, however, are the intellectual property of the individual group members and their sponsoring institutions. Dr. Sahgal has received prior honorarium for educational seminars from Elekta and holds research grants from Elekta.

\section{Authors' contributions}

MG designed the study, performed the data analysis and wrote the manuscript All authors were involved in the data collection. All authors performed critical review of the manuscript and finally approved the manuscript.

\section{Acknowledgments}

We want to thank Dr. Johannes Hain for his continuous support in the statistical analyses.

\section{Author details}

'Department of Radiation Oncology, University of Wuerzburg, Wuerzburg, Germany. ${ }^{2}$ Department Radiation Oncology, University of Pittsburgh Medica Center, Pittsburgh, PA, USA. ${ }^{3}$ Department of Neurological Surgery, University of Pittsburgh Medical Center, Pittsburgh, PA, USA. ${ }^{4}$ Department of Radiation Oncology, Sunnybrook Odette Cancer Centre, Toronto, Canada. ${ }^{5}$ Department of Radiation Oncology, Princess Margaret Hospital, Toronto, Canada. ${ }^{6}$ Department of Radiation Oncology, Beaumont Health System, Oakland University William Beaumont School of Medicine, Royal Oak, MI, USA. ${ }^{7}$ Department of Neurosurgery, Beaumont Health System, Oakland University William Beaumont School of Medicine, Royal Oak, MI, USA. ${ }^{8}$ Department of Neurosurgery, Massachusetts General Hospital, Boston, MA, USA.

${ }^{9}$ Department of Radiation Oncology, Massachusetts General Hospital, Boston, MA, USA. ${ }^{10}$ Department of Neurological Surgery, University of Virginia School of Medicine, Charlottesville, VA, USA. ${ }^{11}$ Riverside Medical Center, Newport News, VA, USA. ${ }^{12}$ Department of Radiation Oncology, University of Zurich, Zurich, Switzerland.

Received: 30 July 2014 Accepted: 30 September 2014 Published online: 16 October 2014

\section{References}

1. Chow E, Harris K, Fan G, Tsao M, Sze WM: Palliative radiotherapy trials for bone metastases: a systematic review. J Clin Oncol 2007, 25(11):1423-1436.

2. Lutz S, Berk L, Chang E, Chow E, Hahn C, Hoskin P, Howell D, Konski A, Kachnic L, Lo S, Sahgal A, Silverman L, von Gunten C, Mendel E, Vassil A, Bruner DW, Hartsell W: Palliative radiotherapy for bone metastases: an ASTRO evidence-based guideline. Int J Radiat Oncol Biol Phys 2011, 79(4):965-976.

3. Bekelman JE, Epstein AJ, Emanuel EJ: Single- vs Multiple-Fraction Radiotherapy for Bone Metastases From Prostate Cancer. JAMA 2013, 310(14):1501-1502.

4. Leithner A, Radl R, Gruber G, Hochegger M, Leithner K, Welkerling H, Rehak P, Windhager R: Predictive value of seven preoperative prognostic scoring systems for spinal metastases. Eur Spine J 2008, 17(11):1488-1495.

5. Hamilton AJ, Lulu BA, Fosmire H, Stea B, Cassady JR: Preliminary clinical experience with linear accelerator-based spinal stereotactic radiosurgery. Neurosurgery 1995, 36(2):311-319.

6. Pan H, Simpson DR, Mell LK, Mundt AJ, Lawson JD: A survey of stereotactic body radiotherapy use in the United States. Cancer 2011, 117(19):4566-4572. 
7. Wang XS, Rhines LD, Shiu AS, Yang JN, Selek U, Gning I, Liu P, Allen PK, Azeem SS, Brown PD, Sharp HJ, Weksberg DC, Cleeland CS, Chang EL: Stereotactic body radiation therapy for management of spinal metastases in patients without spinal cord compression: a phase 1-2 trial. Lancet Oncol 2012, 13(4):395-402.

8. Ryu S, Fang Yin F, Rock J, Zhu J, Chu A, Kagan E, Rogers L, Ajlouni M, Rosenblum M, Kim JH: Image-guided and intensity-modulated radiosurgery for patients with spinal metastasis. Cancer 2003, 97(8):2013-2018.

9. Gibbs IC, Patil C, Gerszten PC, Adler JR Jr, Burton SA: Delayed radiationinduced myelopathy after spinal radiosurgery. Neurosurgery 2009, 64(2 Suppl):A67-A72.

10. Sahgal A, Weinberg V, Ma L, Chang E, Chao S, Muacevic A, Gorgulho A, Soltys S, Gerszten PC, Ryu S, Angelov L, Gibbs I, Wong CS, Larson DA: Probabilities of radiation myelopathy specific to stereotactic body radiation therapy to guide safe practice. Int J Radiat Oncol Biol Phys 2013, 85(2):341-347.

11. Rose PS, Laufer I, Boland PJ, Hanover A, Bilsky MH, Yamada J, Lis E: Risk of fracture after single fraction image-guided intensity-modulated radiation therapy to spinal metastases. J Clin Oncol 2009, 27(30):5075-5079.

12. Cox BW, Spratt DE, Lovelock M, Bilsky MH, Lis E, Ryu S, Sheehan J, Gerszten PC Chang E, Gibbs I, Soltys S, Sahgal A, Deasy J, Flickinger J, Quader M, Mindea S, Yamada Y: International Spine Radiosurgery Consortium consensus guidelines for target volume definition in spinal stereotactic radiosurgery. Int J Radiat Oncol Biol Phys 2012, 83(5):e597-e605.

13. Guckenberger M, Sweeney RA, Flickinger JC, Gerszten PC, Kersh R, Sheehan J, Sahgal A: Clinical practice of image-guided spine radiosurgery-results from an international research consortium. Radiat Oncol 2011, 6:172.

14. Guckenberger M, Goebel J, Wilbert J, Baier K, Richter A, Sweeney RA, Bratengeier K, Flentje M: Clinical outcome of dose-escalated imageguided radiotherapy for spinal metastases. Int J Radiat Oncol Biol Phys 2009, 75(3):828-835.

15. Wong CS, Van Dyk J, Milosevic M, Laperriere NJ: Radiation myelopathy following single courses of radiotherapy and retreatment. Int J Radiat Oncol Biol Phys 1994, 30(3):575-581.

16. Bilsky MH, Laufer I, Fourney DR, Groff M, Schmidt MH, Varga PP, Vrionis FD, Yamada Y, Gerszten PC, Kuklo TR: Reliability analysis of the epidural spinal cord compression scale. J Neurosurg Spine 2010, 13(3):324-328.

17. Boehling NS, Grosshans DR, Allen PK, McAleer MF, Burton AW, Azeem S, Rhines LD, Chang EL: Vertebral compression fracture risk after stereotactic body radiotherapy for spinal metastases. J Neurosurg Spine 2012, 16(4):379-386

18. Cunha MV, Al-Omair A, Atenafu EG, Masucci GL, Letourneau D, Korol R, Yu E, Howard P, Lochray F, da Costa LB, Fehlings MG, Sahgal A: Vertebral Compression Fracture (VCF) After Spine Stereotactic Body Radiation Therapy (SBRT): Analysis of Predictive Factors. Int J Radiat Oncol Biol Phys 2012, 84(3):e343-e349.

19. Haley ML, Gerszten PC, Heron DE, Chang YF, Atteberry DS, Burton SA: Efficacy and cost-effectiveness analysis of external beam and stereotactic body radiation therapy in the treatment of spine metastases: a matched-pair analysis. J Neurosurg Spine 2011, 14(4):537-542.

20. Mizumoto M, Harada H, Asakura H, Hashimoto T, Furutani K, Hashii H, Takagi T, Katagiri H, Takahashi M, Nishimura T: Prognostic factors and a scoring system for survival after radiotherapy for metastases to the spinal column: a review of 544 patients at Shizuoka Cancer Center Hospital. Cancer 2008, 113(10):2816-2822.

21. van der Linden YM, Dijkstra SP, Vonk EJ, Marijnen CA, Leer JW: Prediction of survival in patients with metastases in the spinal column: results based on a randomized trial of radiotherapy. Cancer 2005, 103(2):320-328.

22. Price $P$, Hoskin PJ, Easton D, Austin D, Palmer SG, Yarnold JR: Prospective randomised trial of single and multifraction radiotherapy schedules in the treatment of painful bony metastases. Radiother Oncol 1986, 6(4):247-255.

23. Gaze MN, Kelly CG, Kerr GR, Cull A, Cowie VJ, Gregor A, Howard GC, Rodger A: Pain relief and quality of life following radiotherapy for bone metastases: a randomised trial of two fractionation schedules. Radiother Oncol 1997, 45(2):109-116.

24. Steenland E, Leer JW, van Houwelingen H, Post WJ, van den Hout WB, Kievit J, de Haes H, Martijn H, Oei B, Vonk E, van der Steen-Banasik E, Wiggenraad RG, Hoogenhout J, Warlam-Rodenhuis C, van Tienhoven G, Wanders R, Pomp J, van Reijn M, van Mierlo I, Rutten E: The effect of a single fraction compared to multiple fractions on painful bone metastases: a global analysis of the Dutch Bone Metastasis Study. Radiother Oncol 1999, 52(2):101-109.
25. Roos DE, Turner SL, O'Brien PC, Smith JG, Spry NA, Burmeister BH, Hoskin PJ, Ball DL: Randomized trial of $8 \mathrm{~Gy}$ in 1 versus $20 \mathrm{~Gy}$ in 5 fractions of radiotherapy for neuropathic pain due to bone metastases (TransTasman Radiation Oncology Group, TROG 96.05). Radiother Oncol 2005, 75(1):54-63

26. Auperin A, Le Pechoux C, Rolland E, Curran WJ, Furuse K, Fournel P, Belderbos J, Clamon G, Ulutin HC, Paulus R, Yamanaka T, Bozonnat MC Uitterhoeve A, Wang X, Stewart L, Arriagada R, Burdett S, Pignon JP: Meta-analysis of concomitant versus sequential radiochemotherapy in locally advanced non-small-cell lung cancer. J Clin Oncol 2010, 28(13):2181-2190.

27. Albain KS, Swann RS, Rusch WW, Turrisi AT 3rd, Shepherd FA, Smith C, Chen Y, Livingston RB, Feins RH, Gandara DR, Fry WA, Darling G, Johnson DH, Green MR, Miller RC, Ley J, Sause WT, Cox JD: Radiotherapy plus chemotherapy with or without surgical resection for stage III non-small-cell lung cancer: a phase III randomised controlled trial. Lancet 2009, 374(9687):379-386

28. Garg AK, Shiu AS, Yang J, Wang XS, Allen P, Brown BW, Grossman P, Frija EK, McAleer MF, Azeem S, Brown PD, Rhines LD, Chang EL: Phase 1/2 trial of single-session stereotactic body radiotherapy for previously unirradiated spinal metastases. Cancer 2012, 118(20):5069-5077.

29. Amdur RJ, Bennett J, Olivier K, Wallace A, Morris CG, Liu C, Mendenhall WM: A Prospective, Phase II Study Demonstrating the Potential Value and Limitation of Radiosurgery for Spine Metastases. Am J Clin Oncol 2009.

30. Schipani S, Wen W, Jin JY, Kim JK, Ryu S: Spine radiosurgery: a dosimetric analysis in 124 patients who received 18 gy. Int J Radiat Oncol Biol Phys 2012, 84(5):e571-e576.

31. Heron DE, Rajagopalan MS, Stone B, Burton S, Gerszten PC, Dong X, Gagnon GJ, Quinn A, Henderson F: Single-session and multisession CyberKnife radiosurgery for spine metastases-University of Pittsburgh and Georgetown University experience. J Neurosurg Spine 2012, 17(1):11-18.

32. Chao ST, Koyfman SA, Woody N, Angelov L, Soeder SL, Reddy CA, Rybicki LA Djemil T, Suh $J H$ : Recursive partitioning analysis index is predictive for overall survival in patients undergoing spine stereotactic body radiation therapy for spinal metastases. Int J Radiat Oncol Biol Phys 2012, 82(5):1738-1743.

33. Laufer I, lorgulescu JB, Chapman T, Lis E, Shi W, Zhang Z, Cox BW, Yamada Y, Bilsky MH: Local disease control for spinal metastases following "separation surgery" and adjuvant hypofractionated or high-dose single-fraction stereotactic radiosurgery: outcome analysis in 186 patients. J Neurosurg Spine 2013, 18(3):207-214.

34. Balagamwala EH, Angelov L, Koyfman SA, Suh JH, Reddy CA, Djemil T, Hunter GK, Xia P, Chao ST: Single-fraction stereotactic body radiotherapy for spinal metastases from renal cell carcinoma. J Neurosurg Spine 2012, 17(6):556-564

35. Lovelock DM, Zhang Z, Jackson A, Keam J, Bekelman J, Bilsky M, Lis E, Yamada Y: Correlation of local failure with measures of dose insufficiency in the high-dose single-fraction treatment of bony metastases. Int J Radiat Oncol Biol Phys 2010, 77(4):1282-1287.

36. Yamada Y, Bilsky MH, Lovelock DM, Venkatraman ES, Toner S, Johnson J, Zatcky J, Zelefsky MJ, Fuks Z: High-dose, single-fraction image-guided intensity-modulated radiotherapy for metastatic spinal lesions. Int J Radiat Oncol Biol Phys 2008, 71(2):484-490.

37. Ryu S, Rock J, Rosenblum M, Kim JH: Patterns of failure after single-dose radiosurgery for spinal metastasis. J Neurosurg 2004, 101(Suppl 3):402-405.

38. Al-Omair A, Masucci L, Masson-Cote L, Campbell M, Atenafu EG, Parent A, Letourneau D, Yu E, Rampersaud R, Massicotte E, Lewis S, Yee A, Thibault I, Fehlings MG, Sahgal A: Surgical resection of epidural disease improves local control following postoperative spine stereotactic body radiotherapy. Neuro-Oncol 2013, 15(10):1413-1419.

39. Hwang YJ, Sohn MJ, Lee BH, Kim SY, Seo JW, Han YH, Lee JY, Cha SJ, Kim YH Radiosurgery for metastatic spinal tumors: follow-up MR findings. AJNR Am J Neuroradiol 2012, 33(2):382-387.

doi:10.1186/s13014-014-0226-2

Cite this article as: Guckenberger et al:: Safety and efficacy of stereotactic body radiotherapy as primary treatment for vertebral metastases: a multi-institutional analysis. Radiation Oncology 2014 9:226. 